\title{
Epistemic Modal Verbs in Research Articles WRITTEN BY GHANAIAN AND INTERNATIONAL Scholars: A Corpus-based STUdy OF Three DisCIPLINES
}

\begin{abstract}
This paper discusses epistemic modal verbs as rhetorical markers of argumentation in Ghanaian scholars' research articles (RAs) in the disciplines of Sociology, Economics and Law, and compares the results with similar features in RAs produced by international scholars who are native speakers. In this study, corpus linguistics methods are used to investigate the extent to which Ghanaian scholars' use of epistemic modal verbs differs from international scholars' use of these devices in terms of depth of use, diversity of use, phraseological patterns and degrees of epistemic strength. Statistically examined results show considerable differences in the use of epistemic modal verbs between the two groups of scholars across the disciplines studied, suggesting that the writing practices of the Ghanaian scholars do not fully adhere to international disciplinary conventions. In the conclusion, the theoretical and pedagogical implications of the study are discussed.
\end{abstract}

\section{Keywords}

Academic writing; research articles; epistemic modal verbs; discourse community rhetorical norms; disciplinary variation; intercultural variation

\section{Introduction and research questions}

Owing to the peculiar linguistic characteristics of academic writing, researchers of the rhetoric of academic discourse have in the past three decades or so focused on the language of specialised genres of writing. For example, the undergraduate 
academic essay (Henry and Roseberry 1997; McEnery and Kifle 2002; Hewings 2004; Baker and Chen 2010) and the postgraduate thesis or dissertation (Paltridge 2002; Bunton 2005; Charles 2006; Samraj 2008) have been explored. But perhaps even more attention has gone to professional and expert writing genres, especially the research article (RA) whose centrality as a channel for disseminating new knowledge is now well known. Hewings (2001: 12), for instance, says the RA is "the most important channel for conveying claims of new knowledge".

Studies on the RA conducted by Swales $(1987,1990)$ have been influential, encouraging further work thereafter on the linguistic and textual rhetorical features of the RA (Hyland 1998, 2002; Samraj 2002; Martinéz 2005; Biber, Connor and Upton 2007; Mur-Dueñas 2012; Basturkmen 2012). Much of the research conducted on the RA has focused on how non-native academics, writing in English, utilise these features in their RAs, and has tried to determine the extent to which the rhetorical patterns and choices in the RA texts conform to expected discourse community textual practices, often based on (and dominated by) Anglo-American rhetorical norms (Mauranen 1993; Curry and Lillis 2004; Martinéz 2005; Chovanec 2012). As Chovanec (2012: 7) notes, "linguistic, rhetorical and genre norms are not only expected but are also actively enforced" in academic writing. There is already some research evidence suggesting that non-native English-speaking (NNES) authors often underuse, overuse or misuse (pointing to imprecise and ineffective choices) certain linguistic and rhetorical features in their academic texts (Flowerdew 1999; Martinéz 2005; Leki, Cumming and Silva 2008), thereby not conforming to suitable rhetorical patterns and strategies of scholarly writing in their disciplinary communities. In this respect, while Martinéz, (2005: 175) reports that NNES authors need to "gain a deeper understanding of the social contexts of use of academic texts and the strategic linguistic choices that characterize these texts", Leki et al. (2008: 58) note that L2 scholars "need to control linguistic and rhetorical features of English" in their academic writing. It is suggested that such linguistic and rhetorical challenges in the English academic writing of many NNES scholars partly explain their under-representation in reputable international Anglophone journals (Swales 1987, 1990; Salager-Meyer 2008; Flowerdew and Li 2009).

In this paper, I test the hypothesis that the rhetorical patterns and strategies deployed by NNES writers, especially those based in contexts typically referred to as "off-network" and "peripheral" centres of academic scholarship (Canagarajah 1996, 2002; Flowerdew 1999; Salager-Meyer 2008), do not often adhere to mainstream community practices. Using a corpus-based approach, this paper examines the use of epistemic modal verbs as rhetorical devices for making claims in RAs written in English by NNES Ghanaian authors and published in journals based in Ghana. It tries to understand the ways that the use of these devices by the Ghanaian scholars compares with their use in RAs in prestigious international Anglophone journals written by native English-speaking scholars. I look at writers in Africa (specifically from Ghana) because previous work has virtually ignored this region. 
The challenges and trends of professional academic writing in English in nonnative contexts have largely been reported in Europe, North America and Asia to the neglect of English-speaking contexts in Africa, as in Ghana. In Ghana, a notable ESL country, the RA in English is a key research genre in local universities where Ghanaian-based English-medium journals are highly patronised, yet it is hard to see any existing studies describing the language features of the RA written by Ghanaian scholars. By contrast, there is considerable amount of research conducted on the academic writing of university students. These studies on student academic essays in English have focused on a variety of themes including writing problems of students (Anyidoho 2002), writer identity (Thompson 2003), rhetorical organisation (Afful 2005) and formality (Owusu-Ansah 1992). This paper therefore represents a useful shift in focus, away from student academic writing practices towards practices by professional writers in Ghana. Given that Ghana, and Africa generally, is identified as off-networked, would the rhetorical practices of the Ghanaian writers, as mirrored in the use of epistemic modality, confirm this off-network tag and indicate that they are less aware of centre-based scholarly writing conventions? The paper will thus address three main research questions as follows:

1. What is the relative frequency of epistemic modal verbs in Sociology, Economics and Law research articles written by Ghanaian authors in respect of the:

a. overall incidence of epistemic modals in each discipline?

b. degrees of epistemic modal strength (weak, medium, strong) in each discipline?

2. How do the disciplinary patterns of epistemic modal verb use in the articles written by the Ghanaian authors compare with those in the articles written by international Anglo-American authors?

3. What does a corpus-based analysis tell us about the Ghanaian authors' versatility and overall rhetorical awareness with regards to the use of epistemic modal verbs for academic argumentation in the three disciplines?

\section{Epistemic modality in academic writing}

As Vold (2006: 226) notes, "epistemic modality concerns the reliability of the information conveyed, and epistemic modality markers can be defined as linguistic expressions that explicitly qualify the truth value of a propositional content". With epistemic modality, therefore, the evidence available to a writer [or speaker] determines the level of confidence and force that backs an assertion, a statement or a proposition. Epistemic modality is realised through a vast array of linguistic resources, most notably by modal verbs such as may, would, could, must; but also by adjectives (e.g., possible, likely), adverbs (e.g., possibly, perhaps), lexical verbs (e.g., seem, appear), nouns (e.g., hope, chance), and other non-word 
categories such as phrases and clauses (Biber et al. 1999). In this paper, I focus on epistemic modal verbs.

Epistemic modality forms part of the interpersonal aspect of the three 'functional components of human language (ideational, interpersonal, and textual), referred to in Systemic Functional Linguistics (SFL) as "metafunctions" (Halliday 1994). As Flowerdew (1998: 543) notes, "[t]he interpersonal function is concerned with the writer's attitude to the message and is typically realised through modal verbs (e.g. should, may) and various types of modal adjuncts (e.g. probably, obviously)". Interpersonal rhetorical features have an important place in academic writing; hence researchers of composition theory and the rhetoric of scholarly writing have been interested in how writers employ these interaction features to achieve persuasion, acceptance and ratification by readers. For epistemic modal verbs, academic writers recognise their value by using them (where appropriate) to either mitigate, moderate or strengthen research claims as they seek to persuade their readers to accept the views they are putting across.

The need to use rhetorical devices (e.g. epistemic modal verbs) effectively stems from the awareness that, in scholarly communication, writers do not simply report ideas about some reality in the world, but more crucially, engage in an interaction with readers - especially those readers who are peers of the writer and core members of the discourse community in which the writer is contributing (Bazerman 1988; Myers 1989; Hyland 1998, 2004). As Hyland (2004: 89) notes, at the heart of persuasion in academic writing is the effort by writers to negotiate meaning with readers in ways that will "convey their credibility by establishing a professionally acceptable persona and an appropriate attitude, both to their readers and their argument". To this end, "their sense of audience is critical because gaining acceptance of academic claims involves both rational exposition and the manipulation of rhetorical and interactive features" (Hyland, 1998: 439). Clearly then, familiarity with the persuasive practices and preferred language patterns in one's disciplinary community is critical, and mastery of them is an important first step towards being accepted and recognised as a credible participant in that disciplinary community.

\section{Previous research on epistemic modality in RAs written by non-native authors}

Some research has already been carried out on the use of rhetorical features in RAs written in English by non-native authors. Researchers have explored this topic in different geographical locations (i.e., Europe, Asia, the Middle East, Africa), seeking to understand the rhetorical practices of non-native authors in these regions.

The focus of these studies has been to explore how NNES professionals cope with the challenges of not just writing correctly and proficiently in English, but also demonstrating awareness of (and applying) the stereotypical rhetorical features of academic writing in specific disciplines (Hyland 1995; Flowerdew 1999; 
Uzuner 2008). As English has become the leading language of scholarship in the world today, even scholars in non-English speaking countries find it inescapable to have their best works appear in international English-medium journals. But rhetorical requirements need to be first met. Hyland (1995: 40) makes the point succinctly:

The need to carry out research and publish results in English language journals presents NNSs with serious problems for they have to work within an unfamiliar cultural and linguistic environment. The RA is a key genre in academic disciplines and a NNS who wishes to function in the international research world must be familiar with its conventions [...]

The use of epistemic modality to report claims in an academic argument is one of the features that have been explored in RAs written by NNES scholars (cf. Mirahayuni 2002; Panacová 2008; He and Wang 2013).

Most of the studies suggest that epistemic rhetorical strategies used by NNES authors do not meet the expected specified conventions in the discourse communities concerned. For example, Panacová (2008) compared expressions of epistemic modality in RAs written in English between Slovak and native Englishspeaking scientists in the field of biomedicine. She reports that the distributional differences of epistemic markers in the RAs of the two groups of academics are dramatic. In total, 892 epistemic markers were used by the native English speakers as against 352 by the Slovak scientists. Panacová concludes that Slovak biomedical scientists appear to be overly forceful and direct in making research claims, as they tend to use significantly less epistemic markers than expected.

Overall, non-native scholars' use of epistemic markers in RAs seems to suggest that their English rhetorical practices need improvement if they are to escape the problems of rejection when they submit manuscripts for publication in respected Anglophone journals. Mirahayuni (2002: 311) thus advises that "[n] on-native English writers urgently need to master the discourse aspects of RA writing in order that their research findings gain recognition in the wider research community". From these studies, quite a lot has already been noted about the English rhetorical practices of NNSs in Europe, Asia and the Middle East. However, not much is known about such practices by African scholars in English speaking Africa, with only the studies by Elmalik and Nesi (2008) and Nkemleke (2010) shedding some light. For example, on the use of hedges to mitigate claims in RA abstracts, Nkemleke (2010: 179) states that "Cameroonian scholars seem to lag behind their counterparts abroad in adhering to this style of writing". Indeed, further work is needed to enhance our knowledge and understanding of English rhetorical practices in RAs written by African scholars. In Ghana, a great deal of professional RA writing in English occurs in the universities. This makes it imperative that empirical investigations into the textual practices of the writers are pursued. As this region is one of the geographical locations tagged as "offnetwork" in the academic world, and where writers are non-native speakers of 
English, it would be interesting to compare the textual practices of writers here with those of others elsewhere, especially in "the intellectual centres of the developed countries" (Flowerdew 2001: 122).

As far as I can tell, there is no known study which looks at any aspects of the linguistic and rhetorical features of RAs in English produced by Ghanaian scholars. As I note in my introduction, much work on academic writing in English in the Ghanaian context has focused on the writing practices of students to the neglect of professional authors. The present study therefore aims to fill this gap. I explore how locally-based Ghanaian scholars in the disciplines of Sociology, Economics and Law utilise epistemic modal verbs to make research claims in their RAs. I seek to understand the ways that the use of these rhetorical devices by the Ghanaian authors compares with their use in similar RAs written by international scholars who are native speakers of English. This study will not only practically benefit Ghanaian professional authors (especially in the social sciences), as it may make them more aware of the preferred rhetorical practices for international publication, but will also facilitate English for Professional Academic Purpose (EPAP) (Hyland 2007) research in Ghana.

\section{Corpora and methodology}

\subsection{The corpora}

Two sub corpora of RAs were built and used to carry out this study. One is composed of RAs published in English-medium journals based in Ghana and written by non-native Ghanaian scholars (NNGC), and the other is made up of RAs published in reputable Anglophone journals and written by native Anglo-American speakers (NAAC), who, in this paper, I refer to as 'international scholars'. Each corpus, made up of the three disciplines of Sociology, Economics and Law, totalled around 500, 000 words in size. The overall size of the two sub corpora was approximately 1 million words. Table 1 shows the general shape of the two sub corpora used in this study.

Table 1. Corpora used in the study

\begin{tabular}{|l|l|l|}
\hline Discipline & Ghana (NNGC) & International (NAAC) \\
\hline \multirow{5}{*}{ Sociology } & 23 articles & 20 articles \\
& 132,676 tokens & 147,912 tokens \\
& $\begin{array}{l}\text { Published: 2000-2011 } \\
\text { Source: e.g., Legon Journal of } \\
\text { Sociology, Ghana Social Science } \\
\text { Journal, Oguaa Journal of Social } 2000-2010 \\
\text { Sciences }\end{array}$ & $\begin{array}{l}\text { Source: e.g., American Journal of } \\
\text { Sociology, The British Journal of } \\
\text { Sociology, The Sociological Re- } \\
\text { view, Gender and Society }\end{array}$ \\
\hline
\end{tabular}




\begin{tabular}{|c|c|c|}
\hline Discipline & Ghana (NNGC) & International (NAAC) \\
\hline Economics & $\begin{array}{l}23 \text { articles } \\
145,892 \text { tokens } \\
\text { Published: } 2000-2011 \\
\text { Source: e.g., Journal of Eco- } \\
\text { nomics Studies, Ghana Policy } \\
\text { Journal, Ghana Social Science } \\
\text { Journal, Oguaa Journal of Social } \\
\text { Sciences }\end{array}$ & $\begin{array}{l}20 \text { articles } \\
148,926 \text { tokens } \\
\text { Published: } 2000-2010 \\
\text { Source: e.g., The Quarterly Journal } \\
\text { of Economics, The Review of Eco- } \\
\text { nomic Studies, Journal of Econom- } \\
\text { ic Perspectives, Labour Economics }\end{array}$ \\
\hline Law & $\begin{array}{l}23 \text { articles } \\
168,922 \text { tokens } \\
\text { Published: 2000-2011 } \\
\text { Source: University of Ghana Law } \\
\text { Journal, The Review of Ghana } \\
\text { Law, The KNUST Law Journal }\end{array}$ & $\begin{array}{l}20 \text { articles } \\
221,608 \text { tokens } \\
\text { Published: } 2000-2010 \\
\text { Source: e.g., The American Journal } \\
\text { of International Law, The European } \\
\text { Journal of International Law, Ox- } \\
\text { ford Journal of Legal Studies, Inter- } \\
\text { national Journal of Constitutional } \\
\text { Law }\end{array}$ \\
\hline
\end{tabular}

I tried to ensure that the sub corpora of RAs for the two groups of scholars were comparable, although practical decisions made during the text collection process led to some modifications of the original corpus design. However, these modifications were minor and did not adversely affect or distort the analyses of epistemic modal verbs in the corpus data. Overall, the building of the two sub corpora of RAs reflected the view held by McEnery et al. (2006: 73) that "corpus building is of necessity a marriage of perfection and pragmatism". (For an elaborate account of how these sub corpora were built see Ngula 2015.)

\subsection{Procedure of analysis}

To look for epistemic modal verbs in the two sub corpora of RAs, I started off by consulting previous studies (Hyland and Milton 1997; Rizomilioti 2006) to determine a list of modal verbs with potential epistemic value to form the basis of querying the corpora. A total of 11 forms were derived: could, couldn't, may, might, must, should, shouldn't, would, wouldn't, will, won't. The forms can and can't/cannot were not included for analysis because they rarely occur epistemically and have not been previously listed as epistemic forms (see i.e. Coates 1983; Collins 2009). To be able to answer research question 1(b) effectively, I regrouped the 11 modal forms in terms of three levels/degrees of epistemic force or commitment as follows: must, will, won't (strong), would, wouldn't, should, shouldn't (medium) and could, couldn't, may, might (weak). This three-way grouping of the epistemic modal verbs, according to their degree of likelihood, was adopted based on previous accounts of epistemic scaling (cf. Hyland and Milton 1997; McEnery and Kifle 2002).

Before the analysis of epistemic modal verbs was carried out in the corpora of RAs, I first tagged the corpora for parts of speech (POS tagging) using the CLAWS 7 tagset (Garside 1987). In the initial extraction of modal verbs, the POS tagging 
helped to exclude items that take the form of a modal but are in fact non-modal in use. For example, cases such as will as a noun in the corpus data (e.g. "In other words, rights emanate from the will of the sovereign expressed in positive enactment" [LAW GH04]) were left out in the search for modals. Once every instance of modal verb use had been extracted from the two sub corpora, I further closely examined the concordance lines for each occurring modal to determine epistemic uses over non-epistemic ones. This close reading of concordance lines was crucial as modal verbs in context could be performing other functions aside encoding epistemic meanings. Non-epistemic uses were deleted and hits of genuine epistemic cases recorded. To cite one example, in the Sociology part of the NAAC corpus, the concordance searches carried out returned a total of 1162 uses of modal verbs alone, out of which 785 were used epistemically. (1) and (2) respectively illustrate the epistemic and non-epistemic uses of modal could, for instance:

(1) This difference in search behaviour could adversely affect their reemployment chances. [SOC NA03]

(2) Women created this analogy because they could not control their bodies as much as they could in previous years. [SOC NA17]

Could in (1) expresses epistemic possibility whereas in (2) it carries the root (non-epistemic) sense of ability (Coates 1983). Notably, the modal verbs displayed a wide range of root (or non-epistemic) uses in the RA corpora such as root possibility, ability, tentative wish, obligation, intention, etc. All such nonepistemic uses were left out of the number of genuine epistemic cases recorded for the two groups of scholars.

\section{Results and discussion}

\subsection{Overall frequency of epistemic modal verbs}

Table 2 gives the overall distribution of epistemic modal verbs (together with their normalised frequencies of per 10,000 tokens) in each of the three disciplines of RAs for the two groups of scholars. Figure 1 is a graphical representation of the normalised distribution.

Table 2. Overall distribution of epistemic modal verbs in the two sub corpora

\begin{tabular}{|l|c|c|c|c|}
\hline \multirow{2}{*}{ Discipline } & \multicolumn{2}{|c|}{$\begin{array}{c}\text { Epistemic modal verbs in } \\
\text { international RAs }\end{array}$} & \multicolumn{2}{c|}{$\begin{array}{c}\text { Epistemic modal verbs } \\
\text { in Ghanaian RAs }\end{array}$} \\
\cline { 2 - 5 } & total & per 10,000 tokens & total & per 10,000 tokens \\
\hline Sociology & 785 & 53.07 & 286 & 21.56 \\
\hline Economics & 815 & 54.73 & 420 & 28.79 \\
\hline Law & 1562 & 70.48 & 563 & 33.33 \\
\hline
\end{tabular}




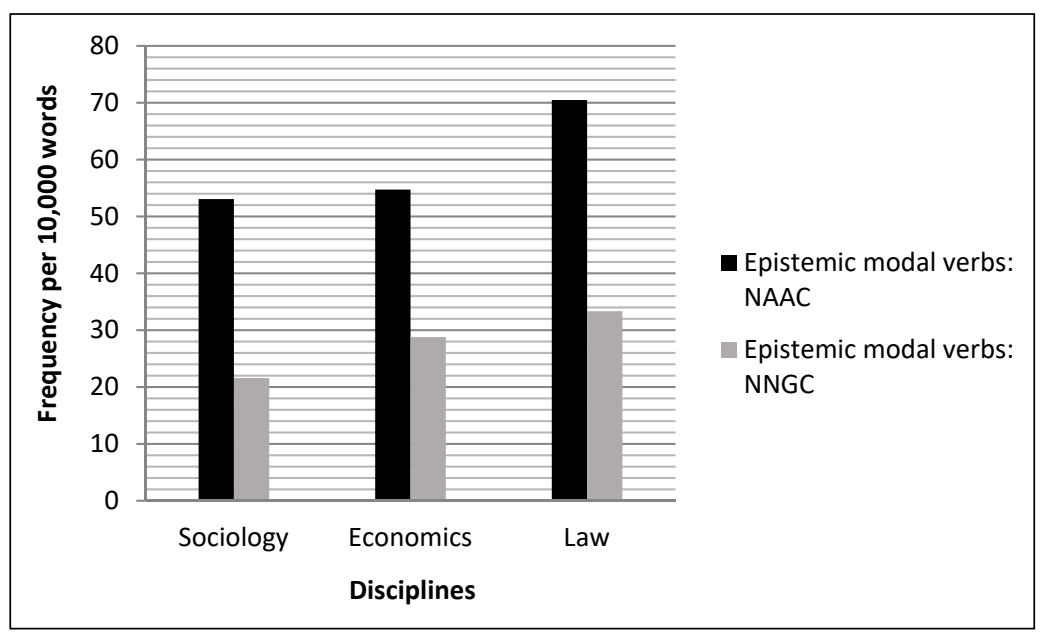

Figure 1. Epistemic modal verbs in the two sub corpora per 10,000 tokens

Before interpreting these results, I should point out that throughout the analysis I determined whether differences of epistemic use, either across disciplines or between authors, were statistically significant or not using the log-likelihood statistical test (Dunning 1993). I specifically used the calculator version developed by Paul Rayson at Lancaster University (available at http://ucrel.lancs.ac.uk/llwizard.html) to compute the figures. The calculator allows the user to statistically compare the frequency of a linguistic feature (e.g., a word or a phrase) in two corpora or sub corpora to test whether an observed difference arises merely due to chance or is indeed a reflection of a significant association between the two corpora. The significance level set for this study was $\mathrm{p}<0.01$ (with a critical value of 6.63).

As can be seen from both Table 2 and Figure 1, when the overall frequency of EMVs in the RAs written by the two groups of scholars is compared, it becomes apparent that the international scholars, in all three disciplinary fields, used considerably more EMVs than their Ghanaian peers. The observed normed differences for each discipline between the two groups of scholars appear to be rather wide, as the international scholars used (31.51) more EMVs in Sociology, (25.94) more EMVs in Economics and (37.15) more EMVs in Law. Table 3 shows the LL results of the overall frequencies of EMV use in the articles written by the two groups of scholars, which further confirms all these apparent differences to be statistically significant. 
Table 3. LL values for EMVs between the two groups of writers

\begin{tabular}{|l|c|c|c|c|}
\hline Discipline & $\begin{array}{c}\text { International } \\
\text { writers }\end{array}$ & $\begin{array}{c}\text { Ghanaian } \\
\text { writers }\end{array}$ & LL-value & $\begin{array}{c}\text { Significance } \\
\text { level: } \mathbf{p}<\mathbf{0 . 0 1}\end{array}$ \\
\hline Sociology & 785 & 286 & 190.65 & Sig. \\
Economics & 815 & 420 & 120.58 & Sig. \\
Law & 1562 & 563 & 256.52 & Sig. \\
Overall & 3162 & 1269 & 587.69 & Sig. \\
\hline
\end{tabular}

These results confirm previous findings (Curry and Lillis 2004; Martinéz 2005; Panacová 2008) and provide further evidence in support of the claim that nonnative speakers often tend to imprecisely either underuse, overuse or misuse important rhetorical features in the RAs they write. The figures derived for the use of EMVs in the RAs examined suggest that Ghanaian RA authors in all three disciplines, in reporting their research claims, tend to use far less EMVs than would be expected in international discourse communities. This may further imply that Ghanaian authors are more direct and overly categorical in the ways that they present research claims, a practice that may not be encouraged in international Anglophone discourse communities.

Let us now turn to frequency of EMVs in terms of disciplinary variation. The incidence of EMVs in the international RAs, as shown in Table 1, suggests a clear difference between the Law articles (70.48) on the one hand and both the Economics (54.73) and Sociology (53.07) articles on the other. While the log-likelihood tests carried out to compare EMVs across the disciplines returned significant differences for Law vs. Economics (LL 35.14)) and Law vs. Sociology (LL 43.28), the difference for Sociology vs. Economics (LL 0.38) turned out to be (statistically) not significant at the $\mathrm{p}<0.01$ level. It would appear, then, that at one independent end of the comparisons (i.e. Sociology vs. Economics), disciplinary variation is not affected by the use of modal verbs in the articles produced by the international authors. However, this influence is most marked in the comparisons of Law vs. Economics and Law vs. Sociology.

The differential patterns of the use of EMVs by the international scholars across the three disciplinary fields seem to correspond with the patterns of use by the Ghanaian scholars, as here too, Law accounts for the highest uses of epistemic modals per 10, 000 words (33.33), followed by Economics (28.79) and then Sociology which records the lowest (21.56). However, for the Ghanaian scholars, the tests carried out to determine whether the differences in the use of EMVs across the three disciplines were statistically significant or not revealed that while the differences for Law vs. Sociology (LL 37.50) and Economics vs. Sociology (LL 14.46) are statistically significant, that for Law vs. Economics (LL 5.19) is not significant at the $\mathrm{p}<0.01$ level. The results here suggest that at two independent ends of the comparisons, the use of EMVs by the Ghanaian scholars affects disciplinary variation. Between the international Economics and Sociology RAs, the difference in the use of EMVs is not wide enough to affect disciplinary variation, this difference between the two disciplines is quite marked in the Ghanaian RAs, thus affecting disciplinary variation. 


\subsection{The commonly used epistemic modal verbs}

Tables 4 and 5 list the top five epistemic modal verbs used in the RAs written by the two groups of authors. Worthy of mention is the fact that such modal verb forms as should and must are generally infrequently used to express epistemic modality (Coates 1983; Hoye 1997; Collins 2009). This is probably true of academic writing too. In the corpora of RAs examined, most of the uses of these modal forms were predominantly non-epistemic, often used to convey the sense of obligation/ necessity, as in examples (3), (4) and (5) from Law, Economics and Sociology.

(3) Everyone agrees that some morally important issues should be settled by legislation. [LAW NA20]

(4) In particular, the public good must be financed by a uniform head tax. [ECO NA08]

(5) In thinking about menopause as a reproductive and aging experience, we must pay attention to structural and ideological shifts in US society. [SOC NA17]

Also, even though the contracted forms won't, wouldn't, couldn't and shouldn't were part of the epistemic resources examined in this study (because they have been listed as having epistemic value), they were conspicuously missing in the RAs explored here. But the non-occurrence of these forms in the RA genre comes as no surprise as they are more likely to be used in conversational and spoken discourse rather than in written academic prose (Biber et al. 1999).

Table 4. Top five modals in NAAC Table 5. Top five modals in NNGC

\begin{tabular}{|c|c|c|c|c|c|}
\hline \multicolumn{3}{|c|}{ International Authors } & \multicolumn{3}{|c|}{ Ghanaian Authors } \\
\hline Modal & Discipline & $\begin{array}{c}\text { Epistemic } \\
\text { occ. f } / \mathbf{1 0 , 0 0 0}\end{array}$ & Modal & Discipline & $\begin{array}{c}\text { Epistemic } \\
\text { occ. f/10,000 }\end{array}$ \\
\hline \multirow{3}{*}{ may } & Sociology & 20.35 & \multirow{3}{*}{ may } & Sociology & 5.73 \\
\hline & Economics & 19.14 & & Economics & 8.16 \\
\hline & \begin{tabular}{|l|} 
Law \\
\end{tabular} & 25.18 & & Law & 10.54 \\
\hline \multirow{3}{*}{ would } & Sociology & 5.00 & \multirow{3}{*}{ will } & Sociology & 5.43 \\
\hline & Economics & 11.89 & & Economics & 8.57 \\
\hline & Law & 17.24 & & Law & 8.05 \\
\hline \multirow{3}{*}{ will } & Sociology & 10.48 & \multirow{3}{*}{ would } & Sociology & 5.73 \\
\hline & Economics & 10.61 & & Economics & 5.28 \\
\hline & Law & 9.61 & & Law & 9.35 \\
\hline \multirow{3}{*}{ might } & Sociology & 10.55 & \multirow{3}{*}{ could } & Sociology & 3.24 \\
\hline & Economics & 4.63 & & Economics & 4.46 \\
\hline & \begin{tabular}{|l|} 
Law \\
\end{tabular} & 12.23 & & Law & 2.37 \\
\hline
\end{tabular}




\begin{tabular}{|l|l|c|l|l|c|}
\hline \multicolumn{3}{|c|}{ International Authors } & \multicolumn{3}{c|}{ Ghanaian Authors } \\
\hline \multirow{2}{*}{ Modal } & Discipline & $\begin{array}{c}\text { Epistemic } \\
\text { occ. f/10,000 }\end{array}$ & \multirow{2}{*}{ Modal } & Discipline & $\begin{array}{c}\text { Epistemic } \\
\text { occ. f/10,000 }\end{array}$ \\
\hline \multirow{3}{*}{ could } & Sociology & 4.73 & \multirow{3}{*}{ might } & Sociology & 1.36 \\
\cline { 2 - 3 } & Economics & 6.18 & Economics & 1.30 \\
\cline { 2 - 3 } & Law & 5.28 & & Law & 1.89 \\
\hline
\end{tabular}

As Tables 4 and 5 show, the corpora of RAs examined revealed that the five most common modal forms used to express epistemic modality are similar between the international and Ghanaian authors although the frequencies in the use of these epistemic forms are radically different for the two groups. In both sub-corpora of RAs, modal verb may is the most common epistemic resource, a finding which confirms its importance as a mitigating device for research claims in academic writing (Hyland 1998; Fløttum et al. 2008). Fløttum et al. (2008: 28) actually note that "modal verb may is considered a typical and dominant marker of epistemic modality". They go further to say that "by choosing epistemic may, the writer presents the content of his or her proposition as possibly true" (Fløttum et al 2008: 28).

But in the corpus data explored for this study, modal verb may exhibits subtle pragmatic differences within its general epistemic possibility (functional) use in these social science fields. The international Law articles, for instance, record the highest cases of modal verb may (25.18) and is used to express weakened prediction as in (6), speculate the cause of something as in (7) and interpret results of analysis as in (8).

(6) International pressure may increase the danger of legislative inertia or nonresponsiveness in the realization of socioeconomic rights. [LAW NA19]

(7) The attraction of rights to public lawyers, and perhaps to theorists of law in general, may be due to their two-dimensional character. [LAW NA14]

(8) That all but seven of the thirty-one developing states that have not become parties to the BWC over the last forty years have chosen to join the CWC regime since it was opened for signature in 1997 may reflect various calculations and assessments... [LAW NA01]

It has to be mentioned though that the overwhelming majority of the epistemic possibility uses of may in the Law articles relate to writers' weakened prediction of what the outcome of an action, event or process might be, as illustrated in example (6). Figure 2 is 20 randomly-selected concordance lines of this pragmatic use of may in the international Law articles. In fact, (7) is the only example of the 'speculation on a cause' use in this set of Law articles whereas only 3 examples are noted of the 'interpretation of result' meaning. The prevalence of the weakened prediction sense of epistemic possibility through modal may in the interna- 
tional Law articles is further testament that legal scholars demonstrate extreme caution in reporting claims.

The international Sociology and Economics writers also used modal verb may considerably, as can be seen from Table 4. In these fields too, the weakened prediction sense is predominant, but the 'interpretation of result' meaning seems more common in these fields than in Law. There are 19 cases in the Sociology articles and 16 occurrences in the Economics articles, as exemplified in (9) and (10).

(9) These results may explain why, contrary to earlier impressions, there appears to be no relation between income distribution and summary measures of mortality across all ages among the countries covered by these data. [SOC NA08]

(10) However, the central concern with the results in Table 1 is that the strong partial correlations between college entrance and civic behaviors may reflect the confounding influence of unobserved determinants of both schooling and civic engagement. [ECO NA16]

\begin{tabular}{|r|c|r|r|}
\hline N & Concordance & File \\
\hline 1 & Further, a focus on any of these rights may produce significant disagreement & LAW NA19.txt \\
\hline 2 & systems, extraordinary circumstances may occasionally warrant a & LAW NA02.txt \\
\hline 3 & programs of action. These instruments may make it easier to press & LAW NA04.txt \\
\hline 4 & of the spectrum, too high a threshold may leave a state at risk, especially & LAW NA03.txt \\
\hline 5 & , it presents a problem that may impede efforts to strengthen the & LAW NA10.txt \\
\hline 6 & fathers in prison about parenting may have a beneficial effect on their & LAW NA08.txt \\
\hline 7 & be confusing since breaches of law may give rise to consequences that & LAW NA04.txt \\
\hline 8 & threats and asymmetrical information may generate or enlarge incentives for & LAW NA01.txt \\
\hline 9 & procedures, the requisite comparisons may fall prey to the will of majorities & LAW NA17.txt \\
\hline 10 & in the employment context only. This may effectively coerce a claimant to & LAW NA15.txt \\
\hline 11 & toward the judicial ideal. But opinions may differ on this last point. & LAW NA20.txt \\
\hline 12 & experiences of mediation, therefore, may differ significantly according to & LAW NA07.txt \\
\hline 13 & de Visscher that custom and treaties may create "objective" rules of & LAW NA04.txt \\
\hline 14 & 207 In this regard, determinacy may contribute to improving the & LAW NA01.txt \\
\hline 15 & , 1998). However, time spent in prison may also provide a suitable & LAW NA08.txt \\
\hline 16 & how a pluralist constitutional ordering may allow for the coordination of the & LAW NA17.txt \\
\hline 17 & have different institutional features that may alleviate, or worsen, particular & LAW NA19.txt \\
\hline 18 & the need to protect intelligence assets, may adversely affect public reporting & LAW NA03.txt \\
\hline 19 & homelessness, adopting one approach may advantage applicants in one case & LAW NA05.txt \\
\hline 20 & fear that other states have achieved, or may achieve, significant technological & LAW NA01.txt
\end{tabular}

Figure 2. Sample concordance lines of the 'weakened prediction' sense of may in NES Law RAs

That the epistemic possibility use of may to specifically encode weakened prediction is the predominant and unmarked sense in the three disciplinary fields might 
be because these disciplines are all within the social sciences, and they tend to be more similar in the way the modal verb is used. We could see more diverging cases if we examined disciplines across the humanities, social sciences and natural sciences with respect to the epistemic uses of may. Also, perhaps the international Sociology and Economics articles applied more of the 'interpretation of result' meaning than the Law articles because of the nature of their research data. Sociology and Economics tend to use more survey and experimental data whose outcome must invariably be directly interpreted by the analyst. Law researchers appear to engage more in content analysis, relying a lot on textual and observational data.

Let us now turn to the modal verb may in the Ghanaian-authored articles in the three fields. As can be seen in Table 5, may is also the most frequently used EMV. However, compared with the distributional pattern in the native articles, the pattern in the Ghanaian articles exhibits both similarities and differences across the disciplines. Like in the native articles, Law articles in the Ghana corpus record the highest uses of may with epistemic meaning (10.54). But unlike in the international articles where Sociologists used epistemic may slightly more than Economists, in the Ghana articles there is a significantly greater occurrence of epistemic may in Economics articles (8.16) than the Sociology articles (5.73).

On the specific sub-meanings of epistemic may, the Ghanaian writers in all three disciplines, like their non-Ghanaian counterparts, also had the weakened prediction sense as the most dominant use. The 'interpretation of result' and 'speculation on a cause' meanings record low frequencies in the three disciplines especially in the Law articles where, while there is no example of the 'interpretation of result' sense, only one example of the 'speculation on a cause' meaning is observed, shown in (11).

(11) In the light of the foregoing difficulties and injustices that may result from the extreme liberal approach to the party of autonomy, laissez fair and freedom of contract were attacked on grounds of monopoly problems ... [LAW GH8]

Furthermore, an interesting use which seems to be more common with the Ghanaian Economics writers relates to the use of epistemic may together with be due to as a way of expressing the 'speculation on a cause' meaning. While this phraseology occurs only once in the international Economics articles, it occurs 6 times in the Ghanaian Economics articles and is used by five different authors, as example (12) illustrates. Figure 3 is a screenshot of the 6 hits in the Ghanaian Economics articles.

(12) This is corroborated by the asset structure implying that MFIs in Ghana with a larger proportion of their assets representing fixed assets perform better in terms of both profitability and outreach. This may be due to the 
creation of branches across the nation and to furnish these offices with the needed equipment and logistics. [ECO GH7]

\begin{tabular}{|r|c|r|r|}
\hline N & Concordance & File \\
\hline 1 & authorities and the negative influence may be due to corruption on the part & ECOGH22.txt \\
\hline 2 & of both profitability and outreach. This may be due to the creation of & ECOGH7.txt \\
\hline 3 & on both profitability and outreach. This may be due to the simple reason that & ECOGH7.txt \\
\hline 4 & returns would change by .03. This may be due to investor preference for & ECOGH4.txt \\
\hline 5 & and investment in the short-run. This may be due to one or a combination & ECOGH3.txt \\
\hline 6 & /NGOs in the water sector, which may be due to the high capital & ECOGH1.txt
\end{tabular}

Figure 3. Screenshot of may be due to in Ghana Economics RAs

Given that this use of epistemic may occurred only once in the international discourse community articles written by Anglo-American authors, I decided to find out whether it is generally infrequent in academic prose. I therefore carried out a corpus search on the word in the academic prose section of the British National Corpus (BNC). The analysis confirms that its rarity in the international Economics articles reflects its infrequent use in academic discourse, even when epistemic may is generally predominant in this genre. Out of 35,278 examples of modal verb may in this section of the BNC, only 76 (representing $0.22 \%$ ) examples of may be due to are found.

With regards to modal verbs will and would, while both are known to be generally quite common in academic prose (Biber et al. 1999), their overall frequencies, as seen in Table 5 above, suggest that the international writers in the three disciplines studied are inclined to use the more tentative form would to express epistemic modality compared with the stronger form will. Generally, when writers use would in its epistemic sense, it portrays them to be more tactful and polite towards claims they make, as the epistemic meaning of would, compared to will, "is less assured and forthright" and "is often used to reduce the [writer's] level of confidence in the truth of the proposition" (Collins 2009: 142). Sentences (13), (14) and (15) exemplify this tentative use of epistemic would by the international Law, Sociology and Economics scholars.

(13) Setting international standards by reference to actual national practice would risk the adoption of very low targets. [LAW NA10]

(14) One would imagine, for example, that the high figure for sociology is partly explained by the attraction of the subject to the politically inclined. [SOC NA11]

(15) Less market power would lead to a smaller increase in the firm's price when there is a change in demand. [ECO NA20] 
However, epistemic will expresses a prediction that is strong and more direct, and is used where writers have enormous confidence in the evidence and knowledge that warrants their claim. As Collins (2009) notes, the strength of epistemic will is comparable to that of must, which as I have already noted, is relatively uncommon in the social science fields explored in this study. Typical examples of epistemic will in the RAs by the international writers are:

(16) Modern sovereign bonds are atomized debt instruments: countries will often know neither the identities nor the nationalities of their bond holders. [LAW NA02]

(17) This privatisation will be difficult to monitor as no official records are kept of private prescriptions. [SOC NA09]

(18) The actual price change that results from this demand shift will also not be directly observable, but can be inferred for any given demand elasticity and supply change. [ECO NA04]

While epistemic would seems to be preferred (compared to will) in the international community articles, the reverse, as Table 5 above shows, seems to be the case for the Ghanaian writers who tend to generally use will more than would for epistemic purposes. This finding further points to the idea that, despite their overall underuse of epistemic resources, the Ghanaian social science authors are more inclined to choosing stronger epistemic devices to make research claims.

From the figures derived for modal verbs might and could in Tables 4 and 5, one can discern that these modal forms are relatively infrequent in all three fields for both groups of authors. However, the overall occurrences of epistemic might and could differ between the two groups. While it appears that the international writers prefer might, more than could, to express epistemic claims, the Ghanaian writers, on the other hand, tend to use could more than might for this purpose. Perhaps the low frequencies observed for these two epistemic modal verbs in these social science fields (compared to, for example may and would) are not a surprising finding since epistemic may, whose epistemic value is like might and could (Palmer 1979; Coates 1983), is an extremely common rhetorical device for social science academic communities. But it should be mentioned that, of the five forms, while might and could record the least number of cases over all three disciplines in the international articles (see Table 4), might, for instance, is slightly less frequent than will in Sociology and Law. It is only with regards to Economics that will records a considerably higher frequency than might.

\subsection{Degrees of epistemic modal strength}

Another dimension looked at in this study is to do with the levels of epistemic force of modal verbs (strong, medium and weak). Strong epistemic claims ex- 
ploit the modal verbs will, must to show a high level of confidence in the truth of the proposition. A common term in the literature for these epistemic devices is 'boosters' (Hyland 1998; Rizomilioti 2006). Weak epistemic claims use the modal forms may, could, might to reduce significantly the level of commitment to the proposition. This has often been discussed in terms of 'hedges' (Hyland 1998; Rizomilioti 2006). The category medium is somewhere between strong and weak and may be expressed with modal forms would, should. Figure 4 gives an overview of the use of EMVs in terms of epistemic force between the two groups of scholars.

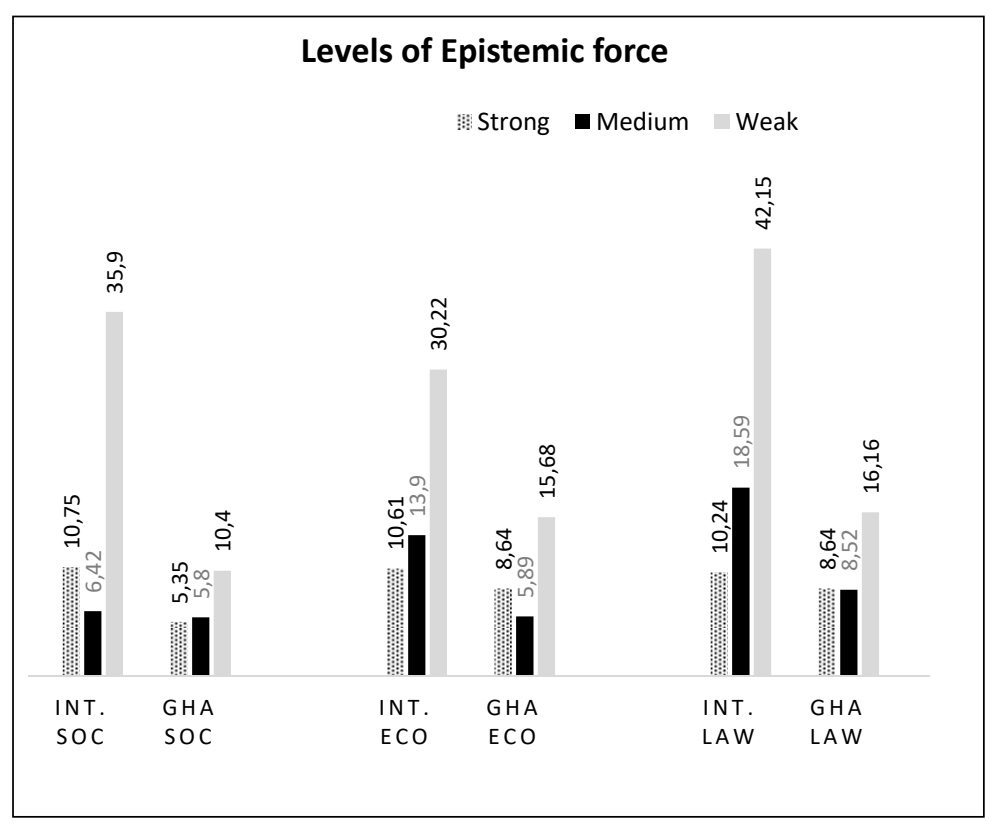

Figure 4. EMVs per epistemic force by the two groups of writers

Perhaps the most notable inference to make of Figure 4, in all three social science disciplines of the two groups of writers, lies in the statistics of weak EMVs. Quite clearly, the findings point to a considerable underuse of weak EMVs by the Ghanaian scholars, compared with their international peers. From Figure 4, one can safely assume that EMVs alone contribute radically to the generally low frequency of weak level epistemic modality devices found in the Ghana articles. It presupposes that the Ghanaian scholars' use of modal verbs such as may, could and might to mitigate or soften research claims needs to be intensified to meet international discourse community expectations. While the use of the medium and strong epistemic verbs between the two groups of scholars is matched, which seems a positive sign for the acceptance of Ghanaian scholars internationally, frequencies in figure 4 suggest that there may still be a need for the Ghanaian scholars to use more of the modal verbs that realise these levels of epistemic force. 


\subsection{The phraseological pattern: May + (Very) Well+ Main Verb/V}

An interesting phraseological pattern of epistemic modal may in the articles produced by the native writers representing international discourse community norms is when it combines with the adverb well (with a possibility of the amplifier very preceding it) and the main verb. Ordinarily, as I have mentioned earlier, may in its epistemic sense generally expresses possibility and can have subtle pragmatic meaning differences. However, when the pattern may + (very) well $+V$ is used, instead of the rather simplified may followed by the main verb, the sense of epistemic modality changes from one of possibility to probability, which in some way results also in the strengthening of the level of epistemicity (cf. Coates 1983; Hoye 1997). Probability is epistemically stronger than possibility. Such specialised patterns may not be so usefully discussed quantitatively, but their discourse value is worth noting.

While in the international discourse community articles in all three disciplines, there are good examples of this use, as in examples (19), (20) and (21), not even a single example of this use occurred in the articles produced by the Ghanaian writers across the three disciplinary fields, although the same Ghanaian writers used may as the most frequent modal verb to express epistemic possibility.

(19) ... or if some have more impact at the earlier stages than others do, conclusions based on current work may very well be mistaken. [SOC NA19]

(20) The actions implemented may well involve lower levels actually carrying them out but this is not modelled. [ECO NA09]

(21) ICSID jurisdiction may well extend to purely contractual disputes as long as the dispute arises directly out of an investment. [LAW NA02]

In the international Law articles, this pattern occurs 15 times (0.68), 8 times in the Sociology articles (0.54) and has 1 example in the Economics articles (0.07). Figure 5 is a screenshot of the 15 examples observed in the international Law articles. 


\begin{tabular}{r|c|c|r|}
\hline N & Concordance & File \\
\hline 1 & adhere rigidly to a formalist approach may well threaten to undermine one of & LAW NA14.txt \\
\hline 2 & From a nation-state perspective, this may well seem a defect, although & LAW NA17.txt \\
\hline 3 & again of the eggshell skull rule). This may well represent an explicit higher & LAW NA16.txt \\
\hline 4 & directly as moral issues. Then we may well not think that courts are the & LAW NA20.txt \\
\hline 5 & distinction that economic transactions may well "involve a fundamental public & LAW NA02.txt \\
\hline 6 & bonds of varying intensity. These links may well include ethnic, religious, & LAW NA17.txt \\
\hline 7 & from one another. Indeed, they may well have contributed to the & LAW NA07.txt \\
\hline 8 & litigation under the Hague Convention may well have been avoided had the & LAW NA07.txt \\
\hline 9 & contractual claims. ICSID jurisdiction may well extend to purely contractual & LAW NA02.txt \\
\hline 10 & allowing legitimacy-based claims may well entail defeat, at least in the & LAW NA14.txt \\
\hline 11 & objectives, a legitimacy-based system may well ensure greater overall & LAW NA14.txt \\
\hline 12 & return proceedings in the first instance may well be discouraged from & LAW NA07.txt \\
\hline 13 & - Under such circumstances, pluralism may well be better served by dividing & LAW NA17.txt \\
\hline 14 & arise in moral life. Such presentation may well be artificial compared to & LAW NA20.txt \\
\hline 15 & that this is not always the case. There may very well be a growing consensus & LAW NA11.txt \\
\hline
\end{tabular}

Figure 5. Screenshot of the may + (very) well $+V$ pattern in Int. Law RAs

I note also that modal verb could exhibits a similar pattern, conveying a meaning almost equivalent to the pattern with may: epistemic probability. But there are only 6 examples of the use of modal could in this way in the entire corpus, and all 6 cases are in the international Law articles, as exemplified in (22):

(22) Willful refusal to abide by contractual obligations, abuse of government authority, and bad faith in the course of contractual performance could well lead to breach. [LAW NA02]

The complete absence of this epistemic pattern in the Ghanaian-authored articles (especially with modal verb may) may be bringing into focus the question of levels of sophistication in the use of certain epistemic forms. The fact that not even a single example occurred in any of the three disciplines of the Ghanaian articles is a strong signal to suggest a certain lack of awareness of the rhetorical effect of such an epistemic pattern in scholarly communication. This could be viewed in line with what Flowerdew (1999) considers to be the non-native speaker's inability to exploit a relatively wide range of expressions to construct certain meanings in English in a sophisticated manner.

\section{Conclusion and implications}

In this paper, I have examined the academic writing practices of Ghanaian L2 professional writers in the disciplines of Sociology, Economics and Law, and shown the extent to which their practices in Ghana adhere to expected international community practices. I specifically looked at how they used epistemic modal verbs as rhetorical resources to make research claims in RAs, aiming to 
test the popular claim by academic writing scholars that the rhetorical patterns and strategies of writers who are NNES often do not meet the stereotypical rhetorical conventions of mainstream communities.

The findings in this study have revealed several important implications relating to theory and pedagogy. Two points on theory: first, the corpus evidence in this study has strengthened the claim that NNES scholars misapply (overuse, underuse, or misuse) rhetorical features of academic writing - EMVs have been considerably underused by the Ghanaian scholars studied. Second, the analysis offered here allows me to propose that rhetorical challenges of academic writing not only affect NNES authors in EFL contexts (e.g., China, Spain) but also those in ESL contexts (e.g., Ghana) where proficiency in the use of English is believed to be higher, compared to EFL contexts. This suggests that advanced proficiency in 'general' English by NNES authors in ESL contexts does not guarantee familiarity with the conventionalised rhetorical strategies required for publishing RAs in reputable Anglophone journals.

In terms of pedagogy, the findings reported here point to the need for priority to be placed on the teaching of the language and rhetoric of the research paper to newly recruited and less-experienced lecturers across different disciplines in Ghana. This can be facilitated by experienced international and local EAP and EPAP specialists. It is easy to assume that such lecturers, who might already be highly proficient as L2 English speakers, can independently negotiate entry into discourse communities and demonstrate awareness of rhetorical conventions in these communities. Such an assumption might simply be wrong and unsustainable. As a long-term measure, research-informed (discipline-specific) academic writing modules for graduate research students in Ghana should be a priority.

Obviously, further research on the rhetorical practices of Ghanaian scholars along the lines of the present work is needed if we are to adequately understand what skills and levels of awareness they might need to effectively negotiate entry into worldwide disciplinary communities for a greater visibility of their research. For now, the evidence derived from this study strongly suggests that, while Ghanaian scholars may have English communication skills and may use English generally well, they are not fully familiar with the conventionalised English rhetorical patterns and strategies required in international disciplinary communities.

\section{References}

Afful, Joseph B. A. (2005) The Rhetoric of Undergraduate Student Writing in a Ghanaian University: A Cross-disciplinary Study. Unpublished PhD thesis. National University of Singapore, Singapore.

Anyidoho Akosua (2002) 'Analysis of the writing of final year students'. Ghanaian Journal of English Studies 1: 58-72.

Baker, Paul and Yu-Hua Chen (2010) 'Lexical bundles in L1 and L2 academic writing'. Language Learning and Technology 14(2), 30-49. 
Basturkmen, Helen (2012) 'A genre-based investigation of discussion sections of research articles in dentistry and disciplinary variation'. Journal of English for Academic Purposes 11(2), 134-144.

Bazerman, Charles (1988) Shaping Written Knowledge. Madison WI: University of Wisconsin Press.

Biber, Douglas, Ulla Connor and Thomas A. Upton (2007) Discourse on the Move: Using Corpus Analysis to Describe Discourse Structure. Amsterdam: John Benjamins.

Biber, Douglas, Stig Johansson, Geoffrey Leech, Susan Conrad and Edward Finegan (1999) Longman Grammar of Spoken and Written English. London: Longman.

Bunton, David (2005) 'The structure of PhD conclusion chapters'. Journal of English for Academic Purposes 4(3), 207-224.

Canagarajah, Suresh (1996) “"Nondiscursive” requirements in academic publishing, material resources of periphery scholars, and the politics of knowledge production'. Written Communication 13(4), 435-472.

Canagarajah, Suresh (2002) The Geopolitics of Academic Writing. Pittsburgh: University of Pittsburgh Press.

Charles, Maggie (2006) 'Phraseological patterns in reporting clauses used in citation: a corpusbased study of theses in two disciplines'. English for Specific Purposes 25, 310-331.

Chovanec, Jan (2012) 'Written academic discourse in English: from local traditions to global outreach'. Brno Studies in English 38(2), 5-16.

Coates, Jennifer (1983) The Semantics of the Modal Auxiliaries. London: Croom Helm.

Collins, Peter (2009) Modals and Quasi-modals in English. Amsterdam: Rodopi.

Curry, Jane M. and Theresa Lillis (2004) 'Multilingual scholars and the imperative to publish in English: negotiating interests, demands, and rewards'. TESOL Quarterly 38(3), 663-688.

ElMalik, Abdullahi T. and Hilary Nesi (2008) 'Publishing research in a second language: the case of Sudanese contributors to international medical journals'. Journal of English for Academic Purposes 7, 87-96.

Fløttum, Kjersti, Trine Dahl, Torodd Kinn, Anje M. Gjesdal and Eva T. Vold (2008) 'Cultural identities and academic voices'. In: Fløttum, Kjersti (ed.) Language and Discipline Perspectives on Academic Discourse. Newcastle upon Tyne: Cambridge Scholars Publishing, 14-39.

Flowerdew, John (1999) 'Problems in writing for scholarly publication in English: the case of Hong Kong'. Journal of Second Language Writing 8(3), 243-264.

Flowerdew, John (2001) 'Attitudes of journal editors to nonnative speaker contributions'. TESOL Quarterly 35(1), 121-150.

Flowerdew, John and Yongyan Li (2009) 'English or Chinese? The trade-off between local and international publication among Chinese academics in the humanities and social sciences'. Journal of Second Language Writing 18, 1-16.

Garside, Roger (1987) 'The CLAWS word-tagging system'. In: Garside, Roger, Geoffrey Leech and Geoffrey Sampson (eds.) The Computational Analysis of English: A Corpus-based Approach. London: Longman.

Halliday, Michael A. K. (1994) An Introduction to Functional Grammar (2nd edn.). London: Edward Arnold.

He, Yuyin and Han Wang (2013) 'A corpus-based study of epistemic modality markers in Chinese research articles', Chinese Lexical Semantics 17717, 199-208.

Henry, Alex and Robert Roseberry (1997) 'An investigation of the functions, strategies and linguistic features of the introductions and conclusions of essays'. System 25(4), 479-495.

Hewings, Ann (2004) 'Developing discipline-specific writing: an analysis of undergraduate geography essays'. In: Ravelli, Louise and Robert Ellis (eds.) Analyzing Academic Writing: Contextualised Frameworks. London: Continuum, 131-152.

Hoye, Leo (1997) Adverbs and Modality in English. London: Longman. 
Hyland, Ken (1995) 'The author in the text: hedging scientific writing'. Hong Kong Papers in Linguistics and Language Teaching 18, 33-42.

Hyland, Ken (1998) 'Boosters, hedges and the negotiation of academic knowledge'. Text 18(3), 349-382.

Hyland, Ken (2004) 'A convincing argument: corpus analysis and academic persuasion'. In: Connor, Ulla and Thomas A. Upton (eds.) Discourse in the Professions: Perspectives from Corpus Linguistics. Amsterdam: John Benjamins, 87-112.

Hyland, Ken (2007) 'English for professional academic purposes: writing for scholarly publication'. In: Belcher, Diane (ed.), Teaching Language Purposefully: English for Specific Purposes in Theory and Practice. New York: Cambridge University Press, 1-27.

Hyland, Ken and John Milton (1997) 'Qualification and certainty in L1 and L2 students' writing'. Journal of Second Language Writing 6(2), 185-205.

Leki, IIona, Alister Cumming and Tony Silva (2008) A Synthesis of Research on Second Language Writing in English. New York: Routledge.

Martinéz, Iliana A. (2005) 'Native and non-native writers' use of first person pronouns in the different sections of biology research articles in English'. Journal of Second Language Writing 14, 174-190.

Mauranen, Anna (1993) 'Contrastive ESP rhetoric: metatext in Finnish-economic texts'. English for Specific Purposes 12, 3-22.

McEnery, Tony and Nazareth A. Kifle (2002) 'Epistemic modality in argumentative essays of second-language writers'. In: Flowerdew, John (ed.) Academic Discourse. London: Longman, $182-195$.

McEnery, Tony, Richard Xiao and Yukio Tono (2006) Corpus-Based Language Studies: An Advanced Resource Book. London: Routledge.

Mirahayuni, Ni K. (2002) Investigating Textual Structure in Native and Non-native English Research Articles: Strategy Differences between English and Indonesian Writers. Unpublished PhD thesis. University of New South Wales, Australia.

Mur-Dueñas, Pilar (2012) 'With regard to L2 academic writing: the use of topicalisers in L2 (English and Spanish) and L2 (English) research articles'. Brno Studies in English 38(2), 117-130.

Myers, Greg (1989) 'The pragmatics of politeness in scientific articles'. Applied Linguistics 10(1), $1-35$.

Ngula, Richmond S. (2015) Epistemic Modality in Social Science Research Articles Written by Ghanaian Authors: A Corpus-Based Study of Disciplinary and Native vs. Non-Native Variations. Unpublished $\mathrm{PhD}$ thesis, Lancaster University, UK.

Nkemleke, Daniel (2010) 'Cameroonian and foreign scholars' discourse: the rhetoric of conference abstracts'. World Englishes 29(2), 173-191.

Owusu-Ansah, Lawrence K. (1992) Variation According to Context: A Study into the Effects of Formality on the English used by Ghanaian Students. Unpublished PhD thesis, University of Edinburgh, UK.

Palmer, Frank (1979) Modality and the English Modals. London: Longman.

Paltridge, Brian (2002) 'Thesis and dissertation writing: an examination of published advice and actual practice'. English for Specific Purposes 21, 125-143.

Panocová, Renáta (2008) 'Expressions of modality in biomedical texts'. SKASE Journal of Translation and Interpretation 3(1), 82-90.

Rayson, Paul: Log-likelihood calculator. Internet: <http://ucrel.lancs.ac.uk/llwizard.html>, 18. 07. 2003.

Rizomilioti, Vassiliki (2008) 'Exploring epistemic modality in academic discourse using corpora'. Information Technology in Languages for Specific Purposes 7, 53-71.

Salager-Meyer, Françoise (2008) 'Scientific publishing in developing countries: challenges for the future'. Journal of English for Academic Purposes 7, 121-132. 
Samraj, Betty (2002) 'Introductions in research articles: variations across disciplines'. English for Specific Purposes 21, 1-17.

Samraj, Betty (2008) 'A discourse analysis of master's theses across disciplines with a focus on introductions'. Journal of English for Academic Purposes 7, 55-67.

Swales, John (1987) 'Utilizing the literatures in teaching the research paper'. TESOL Quarterly 21(1), 41-68.

Swales, John M. (1990) Genre Analysis: English in Academic and Research Settings. Cambridge: Cambridge University Press.

Swales, John M. (2004) Research Genres. Cambridge: Cambridge University Press.

Thompson, Celia (2003) Constructing Critical Discourse and University Students Writing. ANZCA03 Conference, Brisbane, July 2003.

Uzuner, Sedef (2008) 'Multilingual scholars' participation in core/global academic communities: a literature review'. Journal of English for Academic Purposes 7, 250-263.

Vold, Eva T. (2006) 'The choice and use of epistemic markers in linguistics and medical research articles'. In: Hyland, Ken and Marina Bondi (eds.) Academic Discourse Across Disciplines. Bern: Peter Lang, 225-249.

Richmond Sadick Ngula received his PhD in (English) Linguistics from Lancaster University (UK). He also holds MPhil and BA degrees from the University of Cape Coast (Ghana), where he is currently a Lecturer in the Department of English. From September 2014 to October 2016, he was a mentor (learning facilitator) for the FutureLearn online MOOC course Corpus Linguistics: Methods, Analysis, Interpretation, organised by Lancaster University. He has participated in conferences and workshops in Ghana, Portugal, and the UK, and has published research articles in international journals, including Nordic Journal of African Studies and the Southeast Asian Journal of English Language Studies. His research interests are in the areas of academic discourse, corpus linguistics, world Englishes and (critical) discourse analysis.

Address: Richmond Sadick Ngula, Department of English, Faculty of Arts, College of Humanities and Legal Studies, University of Cape Coast, Ghana. [rngula@ucc.edu.gh] 
